\title{
Experimental Study on the Cutting Temperature of Cemented Carbides Tool Embedded With $\mathrm{Caf}_{2}$ Solid Lubricants
}

\author{
Wenlong Song ${ }^{1,2, a}$, Jianxin Deng ${ }^{3, b}$, Xuan Zhang ${ }^{1, c}$, Zongxin Guo ${ }^{1, d}$, Ke Zhou ${ }^{1, e}$ \\ 1DePartment of Mechanical Engineering, Jining University, Qufu 273155, China \\ 2Department of Material Science \& Engineering, Shandong University, Jinan 250061, PR China \\ ${ }^{3}$ Department of Mechanical Engineering, Shandong University, Jinan 250061, China \\ awlsong1981@163.com, bjxdeng@sdu.edu.cn, c13105474878@163.com, \\ dguozhongxin5216@163.com, ezhouke81@163.com
}

\begin{abstract}
Keywords: dry machining, self-lubricated tool, $\mathrm{CaF}_{2}$ solid lubricants, cutting temperature
Abstract. Micro-holes were fabricated using micro-EDM on the surface of WC/TiC/Co carbide, $\mathrm{CaF}_{2}$ solid lubricants were filled into these micro-holes to form self-lubricating tool (MST). Dry cutting tests on AISI 1045 hardened steel were carried out with the MST tools and conventional tools (CT). The cutting temperature were measured and compared. The results indicated that the cutting temperatures with the MST cutting tools were reduced compared with the CT tools, and the cutting speeds were found to have a profound effect on the cutting temperatures variations of the MST tool. Two mechanisms of cutting temperature decrease are found, the first one is due to the formation of a discontinuous $\mathrm{CaF}_{2}$ lubricating film on the tool rake interface, which may decrease the average shear stress; the other one can be inferred from the microholes on the rake face, which contribute to the reduction of contact length at the tool-chip interface
\end{abstract}

\section{Introduction}

Dry machining is an important objective in the industry to reduce environmental pollution and production costs [1,2]. In dry machining, there will be more friction and adhesion between the tool and workpiece compared with fully flooded machining since they will be subjected to higher temperature caused by severe friction between tool and workpiece during machining processes. This will result in increasing tool wear and hence reduction in tool life [2]. It was thought that it was promising to develop self-lubricated tools by forming an in tribological film with low friction between the work material and tool during the machining process [2-9].

Calcium fluoride $\left(\mathrm{CaF}_{2}\right)$ is a well-known and widely used solid lubricant. It has physical, chemical and micro-structural influences on the tribological contact of working surfaces [10]. It has been shown that the additions of $\mathrm{CaF}_{2}$ to the ceramic matrix can improve their tribological properties [9].

In the present study, micro-holes with diameter of about $150 \mu \mathrm{m}$ were made on the surface of the cemented carbide, $\mathrm{CaF}_{2}$ solid lubricants were filled into these micro-holes to form self-lubricating tool (MST). Dry cutting tests on AISI 1045 hardened steel were carried out with the MST tools and conventional tools without micro-holes (CT). The cutting temperature were measured and compared. The mechanisms of reduction of cutting temperature for MST self-lubricated tool were studied.

\section{Experimental Procedures}

Preparation of the Test Samples. Cemented carbide was selected as the test material in this study. Composition, physical, and mechanical properties of this tool material are listed in Table 1. Four micro-holes processed by micro-EDM were fabricated on the surface of the carbide using micro-EDM on the tool-chip contact zone. The diameter of the micro-hole is about $150 \pm 10 \mu \mathrm{m}$, and the depth is about $200 \pm 10 \mu \mathrm{m}$. $\mathrm{CaF}_{2}$ solid lubricants with average diameter of $10 \mu \mathrm{m}$ were filled into the micro-holes by burnishing to form self-lubricating tool (MST). The micro-holes micrograph of cemented carbide tool embedded with $\mathrm{CaF}_{2}$ solid lubricants (MST) and without $\mathrm{CaF}_{2}$ solid lubricants are shown in Fig. 1. 
Table 1 Properties of the cemented carbide tool materials

\begin{tabular}{ccccc}
\hline $\begin{array}{c}\text { Composition } \\
{[\mathrm{wt} \%]}\end{array}$ & $\begin{array}{c}\text { Density } \\
{\left[\mathrm{g} / \mathrm{cm}^{3}\right]}\end{array}$ & $\begin{array}{c}\text { Hardness } \\
{[\mathrm{GPa}]}\end{array}$ & $\begin{array}{c}\text { Thermal conductivity } \\
{[\mathrm{W} /(\mathrm{mK})]}\end{array}$ & $\begin{array}{c}\text { Thermal expansion } \\
\text { coefficient }\left[10^{-6} / \mathrm{k}\right]\end{array}$ \\
\hline $\mathrm{WC}+14 \% \mathrm{TiC}+6 \% \mathrm{Co}$ & 11.5 & 15.5 & 33.47 & 6.51 \\
\hline
\end{tabular}
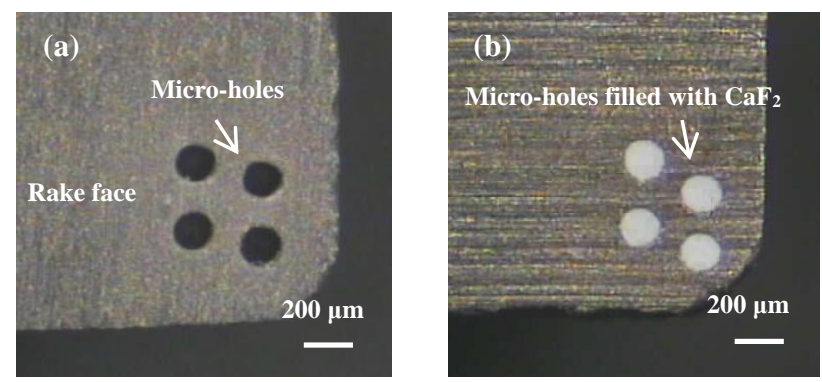

Fig.1 The micro-holes micrograph of MST tool filled (a) without $\mathrm{CaF}_{2}$ (b) with $\mathrm{CaF}_{2}$ solid lubricants

Cutting tests. Cutting tests were carried out on a CA6140 lathe equipped with a commercial tool holder having the following geometry: rake angle $\gamma_{0}=-10^{\circ}$, clearance angle $\alpha_{0}=5^{\circ}$, inclination angle $\lambda_{\mathrm{s}}=5^{\circ}$, side cutting edge angle $k_{\mathrm{r}}=45^{\circ}$. Cutting tools were used with the MST and conventional tool CT for comparison. The workpiece material used was AISI 1045 hardened steel (Chinese standard GB99-88) with a hardness of HRC 35-40. No cutting fluid was used in the machining processes. All tests were carried out with the following parameters: depth of cut $a_{\mathrm{p}}=0.2 \mathrm{~mm}$, feed rate $f=0.1 \mathrm{~mm} / \mathrm{r}$, cutting speed $v=60-140 \mathrm{~m} / \mathrm{min}$, cutting time $5 \mathrm{~min}$.

Cutting temperature were measured by a TH5104R infrared thermal imaging system. Three experiments were carried out for each test. The worn regions of the MST tool embedded with $\mathrm{CaF}_{2}$ solid lubricants were examined using SEM (scanning electron microscope) and EDX (energy dispersive X-ray).

\section{Results and Discussion}

Cutting Temperature. The temperature distribution at the tool-chip interface was measured by the infrared thermal imaging system at $10 \mathrm{~s}$ intervals in dry cutting of hardened steels. The average value of the highest cutting temperatures obtained in each measurement is used as temperature for comparison. Fig. 2 shows the cutting temperature distribution of MST tool in dry cutting hardened steels at speed of $100 \mathrm{~m} / \mathrm{min}$, and the cutting temperature under this cutting condition is about $450 \pm 5{ }^{\circ} \mathrm{C}$ as shown in Fig. 2.

Fig. 3 illustrates the cutting temperature of the CT and MST at different cutting speed. It is evident that the cutting temperature increases with the increasing cutting speeds. The cutting temperature of the MST tool is reduced compared to the CT tool under the same cutting condition.

Cutting speeds seem to have a noted effect on the cutting temperature at the tool-chip interface of the tools. In case of low speed cutting of less than $100 \mathrm{~m} / \mathrm{min}$, the cutting temperature of the MST tool is reduced by $5-10 \%$ compared with that of the CT tool; while in high speed cutting processes of more than $100 \mathrm{~m} / \mathrm{min}$, the cutting temperature is decrease by $10-15 \%$ for the MST tool compared to the CT tool.

Tool Wear Surfaces. The SEM micrograph and EDX element composition analysis of the wear track at the rake face of MST tool after cutting $5 \mathrm{~min}$ at speed of $100 \mathrm{~m} / \mathrm{min}$ is shown in Fig. 4 . Fig. 4 (a) shows the SEM micrograph of the wear track at the tool rake face. It is noted that the wear track exhibits a relatively smooth surface, and the workpiece material adhering onto the tool rake face is not obvious.

The corresponding EDX element composition analysis in Fig. 4 (a) on the worn surface are shown in Fig. 4 (b), (c) and (d). It seems that a thin discontinuous $\mathrm{CaF}_{2}$ lubricating-film is formed on the wear track. The results indicated that $\mathrm{CaF}_{2}$ has been released from the micro-holes and smeared 
unevenly on the rake face. The existence of this discontinuous lubricating-film is helpful to prevent the adhesion of workpiece to the rake face of MST tool.

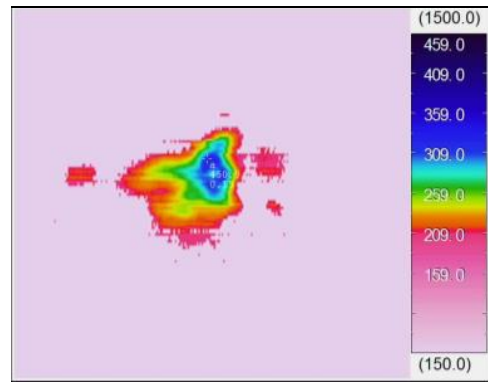

Fig.2 Cutting temperature distribution at the tool-chip interface of MST tool in dry cutting hardened steels $\left(a_{\mathrm{p}}=0.2 \mathrm{~mm}, f=0.1 \mathrm{~mm} / \mathrm{r}, v=100 \mathrm{~m} / \mathrm{min}\right)$

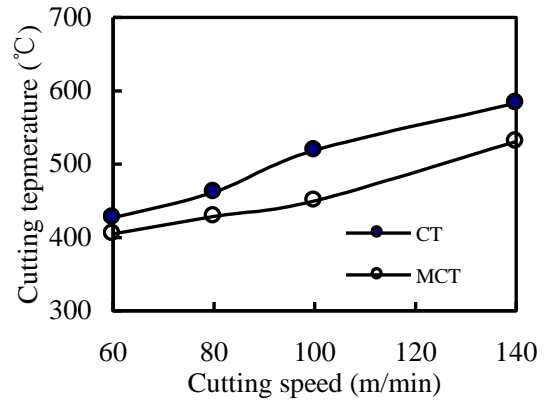

Fig. 3 Cutting temperature of tools in dry cutting hardened steel at different cutting speeds $\left(a_{\mathrm{p}}=0.2 \mathrm{~mm}, f=0.1 \mathrm{~mm} / \mathrm{r}\right.$, cutting time $\left.5 \mathrm{~min}\right)$
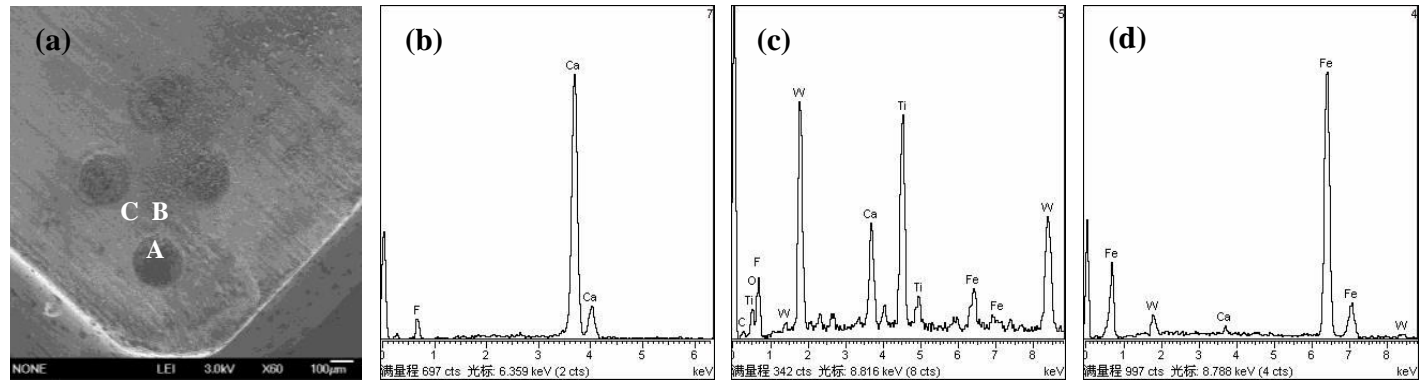

Fig. 4. SEM and EDX element composition analysis on the flank face of MST tool after 5 min dry cutting, (a) SEM micrograph of the wear track, (b) EDX composition analysis in selected area point A, (c) EDX composition analysis in selected area point B, (d) EDX composition analysis in selected area point $\mathrm{C}\left(a_{\mathrm{p}}=0.2 \mathrm{~mm}\right.$, feed rates $\left.f=0.1 \mathrm{~mm} / \mathrm{r}, v=100 \mathrm{~m} / \mathrm{min}\right)$.

\section{Discussion}

In metal cutting process, the cutting heat generation mainly involves three parts [11,12]: chip elastic and plastic deformation on the shear plane, friction along tool-chip interface on the rake face, and friction at tool-workpiece interface on the flank face. Usually, the heat caused by friction between tool flank and workpiece could be ignored for one new tool with smaller tool radius. Then the heat distribution generated in cutting process can be simplified, and the average cutting temperature of chip and tool can be obtained from the formula as:

$$
\begin{aligned}
& \bar{\theta}_{\mathrm{t}}=\bar{\theta}_{s}+\bar{\theta}_{\mathrm{f}}=\theta_{0}+\frac{R_{1} \tau_{\mathrm{s}} \cos \gamma_{\mathrm{o}}}{c_{1} \rho_{1}\left(\sin \left(2 \phi-\gamma_{0}\right)+\sin \gamma_{\mathrm{o}}\right)}+0.7524 R_{2} \bar{\tau}_{\mathrm{c}} \sqrt{\frac{k_{2} v a_{\mathrm{w}} l_{\mathrm{f}}}{c_{2} \rho_{2} \xi}} \\
& \bar{\theta}_{\mathrm{tt}}=\bar{\theta}_{\mathrm{s}}+\bar{\theta}_{\mathrm{ft}}=\theta_{0}+\frac{R_{1} \tau_{\mathrm{s}} \cos \gamma_{\mathrm{o}}}{c_{1} \rho_{1}\left(\sin \left(2 \phi-\gamma_{0}\right)+\sin \gamma_{\mathrm{o}}\right)}+0.7524\left(1-R_{2}\right) \bar{\tau}_{\mathrm{c}} \sqrt{\frac{k_{2} v a_{\mathrm{w}} l_{\mathrm{f}}}{c_{2} \rho_{2} \xi}}
\end{aligned}
$$

where $\bar{\theta}_{\mathrm{t}}$ and $\bar{\theta}_{\mathrm{tt}}$ is the average cutting temperature of chip and tool respectively, $\bar{\theta}_{\mathrm{s}}$ is chip average temperature of shear plane, $\bar{\theta}_{\mathrm{f}}$ and $\bar{\theta}_{\mathrm{ft}}$ is the average temperature rise of chip and tool respectively caused by tool-chip friction. $R_{1}$ is the ratio of heat flow into the chip to the total heat on the shear plane, $\bar{\tau}_{\mathrm{c}}$ is the average shear stress at the tool-chip interface, $v$ is cutting speed, $l_{\mathrm{f}}$ is the contact length at the tool-chip interface, $\gamma_{\mathrm{o}}$ is the rake angle, $c_{1}$ is the chip heat capacity at temperature of $\left(\theta_{0}\right.$ 
$\left.+\bar{\theta}_{S}\right) / 2, \rho_{1}$ is workpiece density, $\phi$ is shear angle, $\tau_{\mathrm{s}}$ is shear strength of the workpiece, $\xi$ is deformation coefficient of the chip, $\theta_{0}$ is ambient temperature, $R_{2}$ is the ratio of heat flow into the chip to the total heat generated by the tool-chip friction, $k_{2}$ is chip thermal diffusivity coefficient at temperature of $\left(2 \bar{\theta}_{\mathrm{S}}+\bar{\theta}_{\mathrm{f}}\right) / 2$, w2 is the chip thermal diffusivity at temperature of $\left(2 \bar{\theta}_{\mathrm{s}}+\bar{\theta}_{\mathrm{f}}\right) / 2$, $\rho_{2}$ and $c_{2}$ is chip density and heat capacity respectively at temperature of $\left(2 \bar{\theta}_{\mathrm{s}}+\bar{\theta}_{\mathrm{f}}\right) / 2$.

The above Eqs. (1) - (2) show that the cutting temperature of chip and tool vary conformably with the average shear stress $\bar{\tau}_{\mathrm{c}}$ and contact length $l_{\mathrm{f}}$ at the tool-chip interface.

The thermal expansion coefficient of $\mathrm{CaF}_{2}\left(18.38 \times 10^{-6} / \mathrm{k}\right)$ is much larger than that of the tool substrate $\left(6.21 \times 10^{-6} / \mathrm{k}\right)$. Under the high cutting temperature and severe chip friction, the $\mathrm{CaF}_{2}$ solid lubricants may be released from the micro-holes, and smeared on the tool face. Then a thin discontinuous $\mathrm{CaF}_{2}$ film may create at the tool-chip interface as shown in Fig. 4, and the average shear stress $\bar{\tau}_{\mathrm{c}}$ will reduce. Meanwhile, the microholes on the MCT tool rake face contributes to the reduction of contact length $l_{\mathrm{f}}$ at the tool-chip interface.

The thermal conductivity of $\mathrm{CaF}_{2}(9.17 \mathrm{~W} /(\mathrm{mK}))$ is smaller than that of the tool substrate $(33.47$ $\mathrm{W} /(\mathrm{mK}))$. Once a thin discontinuous $\mathrm{CaF}_{2}$ film creates at the tool-chip interface, the film has a thermal barrier effect in heat conduction for the tool substrate, which contributes to the temperature reduction and wear resistance. As a result, the cutting temperature of chip and tool on the rake face can be reduced by using the MST tools.

Cutting speeds were found to have an obvious effect on the lubricating performance of the cutting tool, which was probably because the $\mathrm{CaF}_{2}$ solid lubricant is sensitive to cutting temperature. As a lubricating material for high temperature, $\mathrm{CaF}_{2}$ can be effectively carried out excellent lubricating behavior in the range of $450-700{ }^{\circ} \mathrm{C}$ [10]. But under the temperature of $400-450{ }^{\circ} \mathrm{C}, \mathrm{CaF}_{2}$ solid lubricant exhibits relatively poor lubricating performance.

\section{Conclusions}

Micro-holes were fabricated using micro-EDM on the rake face of cemented carbide inserts, and $\mathrm{CaF}_{2}$ solid lubricants were embedded into these micro-holes. Dry cutting tests on hardened steel were carried out with this MST tool and CT tool for comparison. The main conclusions in this study are summarized as follows:

1. Compared with that of the conventional carbide tool (CT), the cutting temperature of the carbide tool embedded with $\mathrm{CaF}_{2}$ solid lubricants (MST) were reduced.

2. Cutting speeds were found to have a noted effect on the cutting performance of the MST tool, which was probably because the $\mathrm{CaF}_{2}$ solid lubricant is sensitive to cutting temperature. In case of low speed cutting of less than $100 \mathrm{~m} / \mathrm{min}$, the cutting temperature of the MST tool were reduced by 5-10\% compared with that of the CT tool; While in high speed cutting processes of more than 100 $\mathrm{m} / \mathrm{min}$, the cutting temperature was decrease by $10-15 \%$ for the MST tool compared to the CT tool.

3. The MST tool exhibits excellent effectiveness in reducing the cutting temperature, and the primary mechanisms responsible are put forward: first, $\mathrm{CaF}_{2}$ solid lubricants may be released from the micro-holes owing to high cutting temperature and chip friction, and created a thin discontinuous $\mathrm{CaF}_{2}$ lubricating film on the tool rake interface, which may decrease the average shear stress; on the other hand, the microholes contribute to the reduction of contact length at the tool-chip interface.

\section{Acknowledgements}

This work was financially supported by the Scientific Research Planning Project of Shandong Province (J16LB02), the China Postdoctoral Science Foundation (2016M592181), the Postdoctoral Innovative Projects of Shandong Province (201603028), and the Scientific Research Foundation of Jining University. 


\section{References}

[1] P.S. Sreejith, B.K.A. Ngoi: Journal of Materials Processing Technology Vol. 101 (2000), p. 287-291.

[2] J.X. Deng, X. Ai, Y.H. Feng: Chinese Journal of Mechanical Engineering Vol. 38 (2002), p. 40-45.

[3] T. Aizawa, A. Mitsuo, S. Yamamoto, et al: Wear Vol. 259 (2005), p. 708-718.

[4] J.X. Deng, W.L. Song, H. Zhang, et al: Int. Journal of Machine Tools \& Manufacture Vol. 48 (2008), p. 1546-1552.

[5] J.X. Deng, W.L. Song, H. Zhang, et al: Wear Vol. 270 (2011), p. 666-674.

[6] Z. Wu, J.X. Deng, C.N. Su, et al: Int. Journal of Refractory Metals and Hard Materials Vol. 45 (2014), p. 238-248.

[7] N.M. Renevier, H. Oosterling: Surface and Coatings Technology Vol. 172 (2003), p. 13-23.

[8] Y.Q. Xing, J.X. Deng, J. Zhao, et al: Int. Journal of Refractory Metals and Hard Materials Vol. 43 (2014), p. 46-58.

[9] J.X. Deng, T.K. Cao, X.F. Yang: Int. Journal of Machine Tool and Manufacture Vol. 46 (2006), p. 957-963.

[10] M. S. Shi, Solid lubricating materials (China Chemical Industry Press, China 2000, In Chinese).

[11] R.Y. Chen, Principle of Metal Cutting (China Machine Press, China 1992, In Chinese).

[12] K. Nakayama, Principle of Metal Cutting (China Machine Press, China 1992, In Chinese). 